\title{
Primary lung carcinoma with tracheal bronchus treated with uniportal video-assisted thoracoscopic upper lobectomy: a case report
}

\author{
Benedict Dharmaraj, Narasimman Sathiamurthy, Nguk Chai Diong, Narendran Balasubbiah \\ Thoracic Surgery Unit, Department of Surgery, Hospital Kuala Lumpur, Kuala Lumpur 50586, Malaysia. \\ Correspondence to: Dr. Benedict Dharmaraj, Thoracic Surgery Unit, Department of Surgery, Hospital Kuala Lumpur, Jalan \\ Pahang, Kuala Lumpur 50586, Malaysia. E-mail: darwin845@yahoo.com \\ How to cite this article: Dharmaraj B, Sathiamurthy N, Diong NC, Balasubbiah N. Primary lung carcinoma with tracheal \\ bronchus treated with uniportal video-assisted thoracoscopic upper lobectomy: a case report. Mini-invasive Surg 2020;4:65. \\ http://dx.doi.org/10.20517/2574-1225.2020.51
}

Received: 26 May 2020 First Decision: 18 Jun 2020 Revised: 21 Jun 2020 Accepted: 29 Jun 2020 Published: 12 Oct 2020

Academic Editor: Noriyoshi Sawabata Copy Editor: Cai-Hong Wang Production Editor: Tian Zhang

\begin{abstract}
Tracheal bronchus is a rare, congenital abnormality of the tracheobronchial tree. Majority of patients with tracheal bronchus are asymptomatic. Lung malignancy associated with tracheal bronchus is rare. An asymptomatic 40-year-old female was diagnosed with right upper lobe lung carcinoma. CT thorax revealed a right upper lobe tracheal bronchus. The patient underwent right uniportal video-assisted thoracoscopic (VATS) lobectomy and recovered well. To our knowledge, this is the first reported case of primary lung carcinoma with tracheal bronchus treated with right uniportal VATS upper lobectomy in Malaysia, and the second reported case internationally.
\end{abstract}

Keywords: Case report, tracheal bronchus, primary lung carcinoma, uniportal video-assisted thoracoscopic, lobectomy

\section{INTRODUCTION}

Bronchovascular variations exists in the general population but are often only diagnosed pre- or intraoperatively. Tracheal bronchus is a rare congenital variation of the bronchial tree structure and can be seen in $0.1 \%-3 \%$ of population ${ }^{[1-5]}$. Primary lung cancer in association with tracheal bronchus is an even rarer entity $^{[1,6,7]}$. We present a case of a middle-aged female with right upper lobe carcinoma, tracheal bronchus and other bronchovascular variations, who underwent uniportal video-assisted thoracoscopic (VATS) right upper lobectomy and lymphadenectomy.

\footnotetext{
(@) $\odot$

(C) The Author(s) 2020. Open Access This article is licensed under a Creative Commons Attribution 4.0 International License (https://creativecommons.org/licenses/by/4.0/), which permits unrestricted use, sharing, adaptation, distribution and reproduction in any medium or format, for any purpose, even commercially, as long as you give appropriate credit to the original author(s) and the source, provide a link to the Creative Commons license, and indicate if changes were made.
}

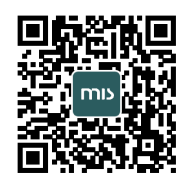




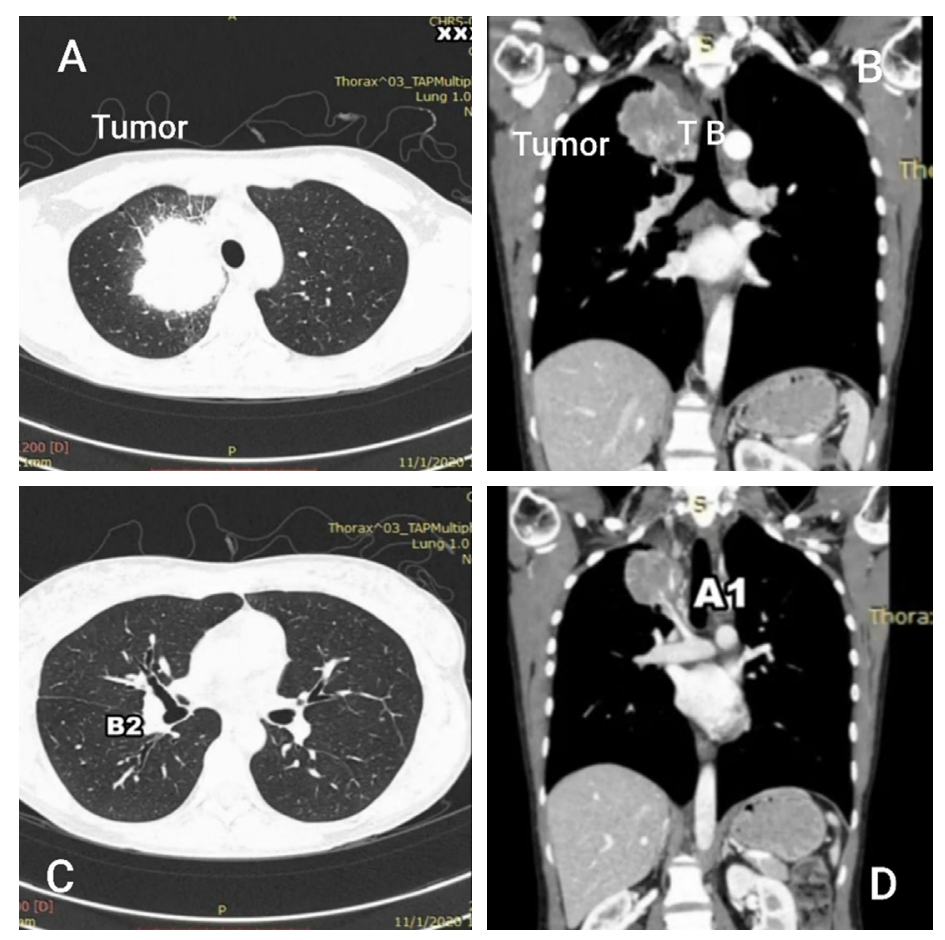

Figure 1. $A$ : axial view of $C T$ thorax showing a right upper lobe mass; $B$ : coronal view of $C T$ showing right upper lobe mass and tracheal bronchus; C: axial view of CT showing posterior segment bronchus (B2) originating from intermedius bronchus; D: coronal view of CT thorax showing artery to apical segment (A1) arising from the right main pulmonary artery. TB: tracheal bronchus

\section{CASE REPORT}

A 40-year-old female was referred to our Thoracic Surgery unit for right upper lobe carcinoma. She initially presented to a primary health care centre with digital clubbing, but no other respiratory symptoms. The patient was a chronic smoker, with a 20 pack year history.

Besides digital clubbing, the patient's physical examination was unremarkable. A chest radiograph revealed a large right upper lobe lesion. Subsequently, a CT thorax revealed a right upper lobe mass, measuring $5.6 \mathrm{~cm} \times 5.1 \mathrm{~cm} \times 5.7 \mathrm{~cm}$ [Figure 1A]. CT-guided biopsy of the lesion was performed, and histopathological examination determined the lesion to be an adenocarcinoma. PET CT demonstrated localized disease.

The patient's lung function test was acceptable, with a predicted postoperative forced expiratory volume in one second (PPOFEV1) of $81 \%$ for right upper lobectomy. Her CT was reviewed in the Thoracic Surgery outpatient clinic, and it was then noted that the patient had a right upper lobe bronchus originating from the trachea, a tracheal bronchus [Figure 1B].

The patient underwent uniportal VATS right upper lobectomy and lymphadenectomy. Intraoperatively, the tumor measured $6 \mathrm{~cm} \times 7 \mathrm{~cm}$ [Figure 2] and both the oblique and horizontal fissures were completely fused. Besides the tracheal bronchus, other anatomical variations were found. The posterior segmental bronchus (B2) was noted to be originating from the bronchus intermedius [Figures $1 \mathrm{C}$ and $3 \mathrm{C}$ ], and the $\mathrm{A} 1$ artery was seen to be originating from the right main pulmonary artery [Figures $1 \mathrm{D}$ and $3 \mathrm{D}$ ], while the $\mathrm{A} 2$ and $\mathrm{A} 3$ were from the truncus anterior [Figure 3D]. Lymph nodes at stations $2 \mathrm{R}, 4 \mathrm{R}, 7,8$ and 10 were dissected and cleared.

Surgery was performed entirely via uniportal VATS, with blood loss of approximately $100 \mathrm{~mL}$. The patient's post-operative recovery was uneventful, and she was discharged home well on post-operative day 5 . The 


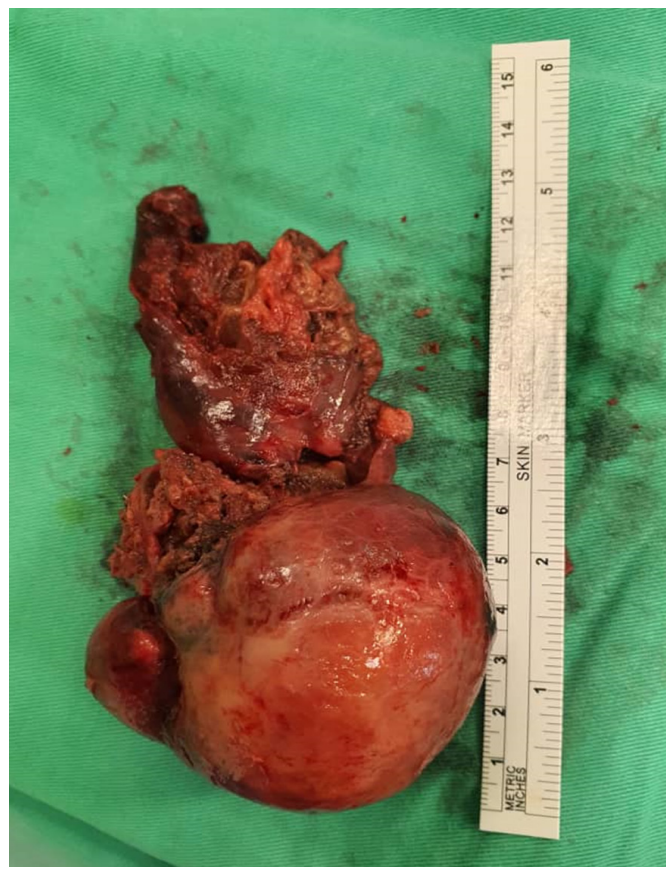

Figure 2. Resected right upper lobe with tumor
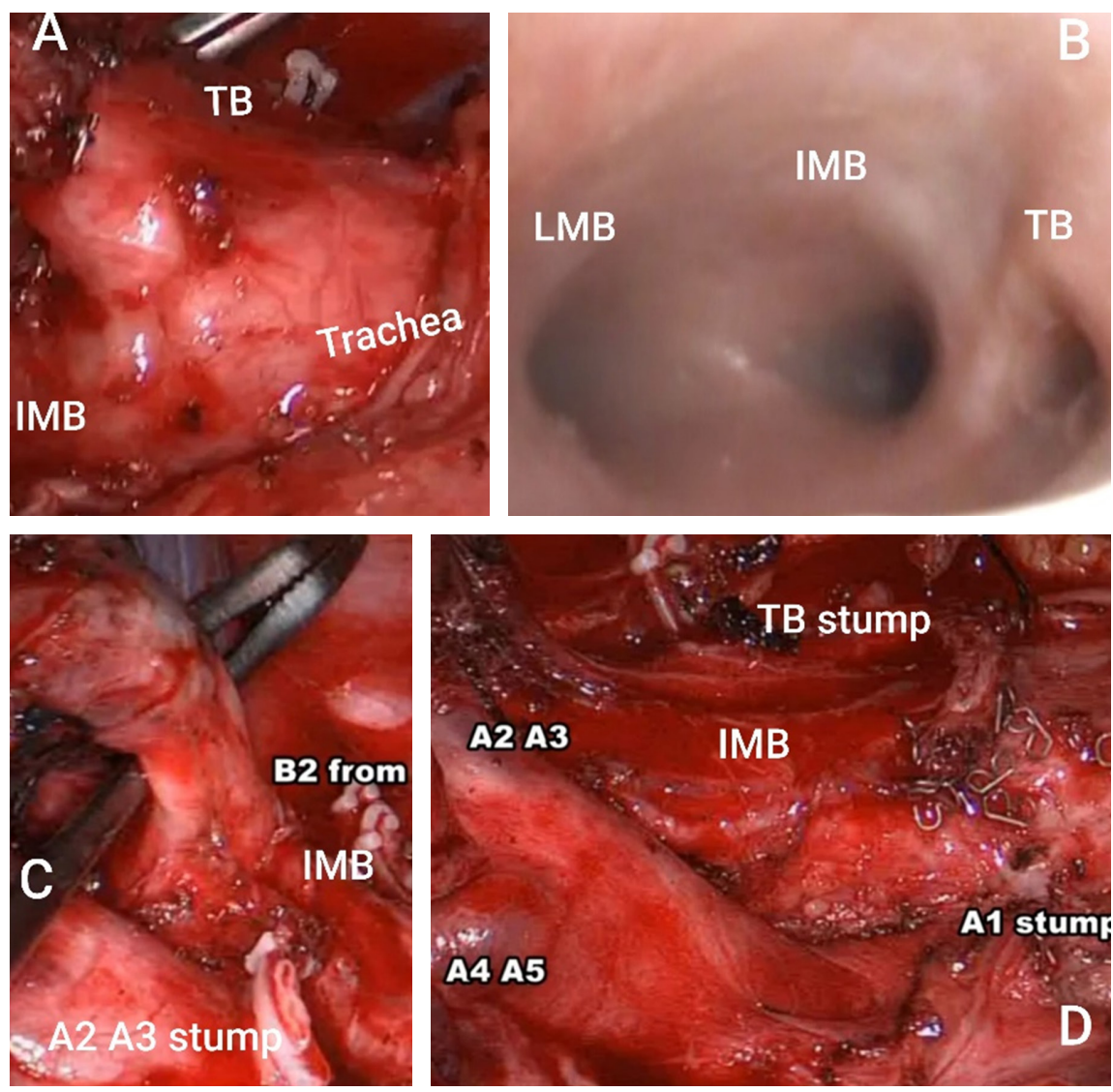

Figure 3. $A$ : shows the TB arising from the trachea; $B$ : an intraoperative bronchoscopy image which shows a right tracheal bronchus; $C$ : shows the posterior segment bronchus (B2) arising from the intermedius bronchus; D: shows the arterial and bronchial supply postresection. TB: tracheal bronchus; IMB: intermedius bronchus; LMB: left main bronchus 
histopathological diagnosis was solid type adenocarcinoma, $\mathrm{T} \mathrm{NO}_{(0 / 2)} \mathrm{MO}$ based on TNM staging, which translates to Stage IIB disease. The patient was later referred to an oncologist for adjuvant therapy. The surgical video is available for viewing at https://youtu.be/93xKNmBR4Ns.

\section{DISCUSSION}

Tracheal bronchus was first described by Sandifort in $1758^{[1-3]}$. This condition is also known as bronchial suis or pig bronchus. It is a rare congenital anomaly, described as an ectolupic bronchus arising from the lateral wall of the trachea, proximal to the carina. The incidence of tracheal bronchus is reported to be between $0.1 \%-3 \%^{[1-5]}$.

Trachel bronchus more commonly occurs on the right side $(0.1 \%-3 \%)$ than the left $(0.3 \%-1 \%)^{[3,8]}$. Tracheal bronchus can arise anywhere between the carina and the cricoid cartilage, most commonly $2 \mathrm{~cm}$ from the carina. The highest origin of tracheal bronchus reported was $6 \mathrm{~cm}$ from the carina ${ }^{[9]}$. Tracheal bronchus is also associated with other congenital abnormalities like Down's syndrome, tracheoesophageal fistula, VATER (vertebra, anus, trachea, esophagus, renal) syndrome, esophageal atresia, laryngeal and duodenal webs, spinal fusion defects and congenital cardiac defects ${ }^{[3,4,8,9]}$. Amongst patients with tracheal bronchus, $69 \%$ have associated cardiac disease, $35 \%$ have associated chromosomal abnormalities and $11 \%$ have spinal fusion defects.

Generally, tracheal bronchus can be classified into displaced and supernumerary types. In the displaced type, there is a missing segmental bronchus from the right upper lobe bronchus. In the supernumerary type, the right upper lobe bronchus trifucates into apical, posterior and anterior segmental bronchi ${ }^{[7,9,10]}$. The patient in this case report had a displaced tracheal bronchus, as the posterior segmental bronchus originated from the intermedius bronchus.

Another categorization of tracheal bronchus considers the distance of the tracheal bronchus origin from the carina. According to this classification, tracheal bronchus is divided into 3 types: (1) Type I: tracheal bronchus originates more than $2 \mathrm{~cm}$ from the carina, with narrowing of the distal trachea; (2) Type II: tracheal bronchus originates more than $2 \mathrm{~cm}$ from the carina, no narrowing of the distal trachea; (3) Type III: tracheal bronchus originates less than $2 \mathrm{~cm}$ above the carina.

Majority of patients with tracheal bronchus are asymptomatic. Symptomatic patients usually present with recurrent chest infections due to retained secretions. Symptomatic children usually present with stridor and recurrent pneumonia ${ }^{[1,2,6,8,10]}$. Treatment is advocated for patients with severe, recurrent symptoms, with definite treatment being an upper lobectomy. Asymptomatic patients do not require intervention. Despite being asymptomatic, our patient required intervention due to the incidental mass found on chest X-ray.

Presence of a tracheal bronchus may present a challenge for anesthetists as problems can arise during intubation. The anomalous bronchus may get occluded by the endotracheal tube, resulting in right upper lobe collapse and shunting. Accidental intubation of the anomalous bronchus can also lead to pneumothorax $^{[5,7,10]}$.

Malignancy arising from a tracheal bronchus is rare. Besides malignancy, there have also been case reports on tuberculosis, leiomyoma and massive hemoptysis associated with tracheal bronchus ${ }^{[7]}$. To date, less than 20 cases of primary lung malignancy associated with tracheal bronchus have been reported. Uchikov et al. ${ }^{[1]}$ in Bulgaria was the first to report a case of lung malignancy arising from tracheal bronchus in 1974. The second case report in the world was published in 1985 by Moriya et al. ${ }^{[12]}$, regarding a Japanese patient with small cell lung cancer which was seen originating from a tracheal bronchus. Due to the rarity of this pathology, no studies have been performed to investigate the association between a tracheal bronchus and 
primary lung malignancy ${ }^{[6]}$. Yurugi et al. ${ }^{[2]}$ were the first to report a case of VATS right upper lobectomy for lung cancer with tracheal bronchus, utilizing a 5-port technique. Huang et al. ${ }^{[1]}$ were the first to report a case of uniportal right VATS upper lobectomy for lung cancer associated with tracheal bronchus. To date, this is the first case report from Malaysia, and to the authors' best knowledge, the second case report internationally, of a patient with primary lung carcinoma, with a tracheal bronchus, to have undergone right upper lobectomy via uniportal VATS.

Variations in bronchovascular patterns are common, hence it is important for a thoracic surgeon to look out for these variations, both pre- and intra-operatively, in order to prevent devastating outcomes. In a study by Nagashima et al. ${ }^{[13]}$, bronchovascular patterns of the right upper lobes of 263 patients were reviewed using 3D CT angiography and bronchography images. Based on their study, 71.9\% (189 patients) had the usual pulmonary artery branching, and $44.1 \%$ (116 patients) had the usual upper lobe bronchial branching, as classically described in most textbooks ${ }^{[13]}$. The remaining patients had variations in bronchovascular supply to the right upper lobe. In $13.3 \%$ of patients, the origin of A1 and A3 varied, as in the subject of this case report.

In conclusion, primary lung carcinoma with associated tracheal brochus is rare. A myriad of other bronchovascular variations exists, with or without an associated tracheal bronchus. It is imperative for thoracic surgeons to have thorough knowledge on bronchovascular pattern variations, and to perform thorough dissection during surgery in order to avoid devastating outcomes. In the hands of an experienced surgeon, with detailed preoperative planning, uniportal VATS lobectomy can be safely performed with good outcomes and low morbidity.

\section{DECLARATIONS}

\section{Authors' contributions}

Collected and selected articles: Dharmaraj B

Participated in manuscript, writing and review: Dharmaraj B, Sathiamurthy N, Diong NC, Balasubbiah N

Participated in review: Dharmaraj B, Sathiamurthy N

\section{Availability of data and materials}

Not applicable.

\section{Financial support and sponsorship}

None.

\section{Conflicts of interest}

All authors declared that there are no conflicts of interest.

\section{Ethical approval and consent to participate}

Approval obtained from the office of the Director and the hospitals' ethics committee to proceed with this analysis and publication.

\section{Consent for publication}

The author(s) declared that informed consent has been taken from the patient for usage of peri-operative data and images for publication purpose.

\section{Copyright}

(c) The Author(s) 2020. 


\section{REFERENCES}

1. Huang L, Zheng J, Hu R, Jiang H, Wei D, et al. Uniportal video-assisted thoracoscopic surgery for lung neoplasms with tracheal bronchus: a case report. Transl Cancer Res 2020;9.

2. Yurugi Y, Nakamura H, Taniguchi Y, Miwa K, Fujioka S, et al. Case of thoracoscopic right upper lobectomy for lung cancer with tracheal bronchus and a pulmonary vein variation. Asian J Endosc Surg 2012;5:93-5.

3. Nicolaou N, Du Plessis A. Squamous carcinoma arising from a true tracheal bronchus: management and case report. Int J Surg Case Rep 2015;6C:256-8.

4. Kuo CW, Lee YC, Perng RP. Tracheal bronchus associated with lung cancer: a case report. Chest 1999;116:1125-7.

5. Agarwal S, Banks MA, Dalela S, Bates WB, Castresana MR. Incidental finding of tracheal bronchus complicating the anesthetic management of a left video-assisted thoracoscopic procedure. J Anaesthesiol Clin Pharmacol 2016;32:106-8.

6. Kim J, Park C, Kim H, Lee KS. Surgical resection of lung cancer originating in a tracheal bronchus. Ann Thorac Surg 1998;66:944-6.

7. Sindhwani G, Rawat J, Gupta M, Chandra S. Lung cancer in "true tracheal bronchus": a rare coincidence. J Bronchology Interv Pulmonol 2012;19:340-2.

8. Sedighi I, Olfat M, Pak N, Esfahany MN. Tracheal bronchus associated with unilateral absence of pulmonary artery and recurrent pneumonia. J Compr Ped 2016;7:e37092.

9. Wong D, Kumar A. Case report: endotracheal tube malposition in a patient with tracheal bronchus. Can J Anaesth 2006;53:810-3.

10. Doolittle AM, Mair EA. Tracheal bronchus: classification, endoscopic analysis, and airway management. Otolaryngol Head Neck Surg 2002;126:240-3.

11. Uchikov P, Nikolov P. A case of carcinoma developing from the base of an anomalous tracheal bronchus. Khirurgiia (Sofiia) 1974;27:31920.

12. Moriya H, Kato H, Togawa T. Small cell lung cancer arising in an abnormal bronchus. Jpn J Chest Dis 1985;44:1035-9.

13. Nagashima T, Shimizu K, Ohtaki Y, Obayashi K, Kakegawa S, et al. An analysis of variations in the bronchovascular pattern of the right upper lobe using three-dimensional CT angiography and bronchography. Gen Thorac Cardiovasc Surg 2015;63:354-60. 